Editorial

\title{
Dark matter of the brain-silent neurons?
}

\section{The silent neurons}

The neuronal signalling is based on the fundamental electrical activity as this activity differentiates neurons from other types of cells. But the Human brain, there are numerous neurons that do not fire action potential, they are far more silent than generally thought. Such neurons as called the dark neurons or silent neurons. They form the dark matter of the brain. While conducting the representative neurological experiments these "dark" neurons do not fire, thus their role in brain function is questioned by the scientists. ${ }^{1}$

\section{The concept of 'sparse coding'}

The 'sparse firing' concept is employed in describing the physiology of the silent neurons. It proposes that a particular stimulus given to neurons only triggers activation only in a small group of neurons. Whereas the non-sparse coding is defined as that a particular stimulus activates several group of neurons, in varying degrees of activation.

The presence of silent neurons suggests sparse coding - but presence of sparse coding does not confirm the existence of silent neurons. According to the theory of sparse coding, to any given single stimulus, a large group of neurons will be silent in retort. According to Barth and Poulet the section of reactive neurons may be miscalculated due to the fact the stimulus given during the experiment may not be appropriate enough to stimulate all the neurons that are studies. To clear this out, if the neurons are truly silent that doesn't respond to any stimulus, all the likely stimuli has to be tested on those neurons. ${ }^{2}$

\section{Evolutionary significance of silent neurons}

Scientists related the silent or nonreactive set of neurons with the phylogenetic past. According to them, immense assemblages of such petrified neurons and neuronal networks could have been a part of the fundamental fragment of well-organized neuronal circuits that had a major adaptive role in one's own life affairs. This dark matter of
Volume 6 Issue 2 - 2019

\author{
Divya R,' AshokV,' Rajajeyakumar $\mathrm{M}^{3}$ \\ 'Department of Physiology, Karpagam Faculty of medical \\ sciences and research, India \\ ${ }^{2}$ Department of Biochemistry, Karpagam Faculty of medical \\ sciences and research, India \\ ${ }^{3}$ Department of Physiology, Trichy SRM Medical College Hospital \\ \& Research Centre, India
}

Correspondence: Rajajeyakumar M,Assistant professor, Department of Physiology, SRM Medical College Hospital \& Research Centre, Trichy, MGR Medical University, Chennai, Tamil Nadu, India,Tel +0975 I382650, Email rajakumar60@gmail.com

Received: March 19,2019 | Published: March 29, 2019

the brain may epitomize primeval circuits of neural network that was consolidated behind the times. The exact reason behind such petrified brain circuits could be Neuronal inhibition for clampdown of brain activity. ${ }^{3}$

\section{Acknowledgments}

None.

\section{Conflicts of interest}

The authors declare there is no conflict of interest.

\section{References}

1. Shoham S, O'Connor DH, Segev R. How silent is the brain: is there a "dark matter" problem in neuroscience? J Comp Physiol A Neuroethol Sens Neural Behav Physiol. 2006;192(8):777-784.

2. Barth AL, Poulet JF. Experimental evidence for sparse firing in the neocortex. Trends Neurosci. 2012;35(6):345-355.

3. Ovsepian SV. The dark matter of the brain. Brain Struct Funct. 2019. 